\title{
Prognostic Value of The Ratio of Maximum To Minimum Diameter of Primary Tumor In Metastatic Clear Cell Renal Cell Carcinoma
}

\section{Hongzhe Shi}

National Cancer Center/National Clinical Research Center for Cancer/Cancer Hospital

Chuanzhen Cao

National Cancer Center/National Clinical Research Center for Cancer/Cancer Hospital

Li Wen

National Cancer Center/National Clinical Research Center for Cancer/Cancer Hospital

Lianyu Zhang

National Cancer Center/National Clinical Research Center for Cancer/Cancer Hospital

Jin Zhang

National Cancer Center/National Clinical Research Center for Cancer/Cancer Hospital

Jianhui Ma

National Cancer Center/National Clinical Research Center for Cancer/Cancer Hospital

Jianzhong Shou ( $\nabla$ shoujzh2021@163.com )

National Cancer Center/National Clinical Research Center for Cancer/Cancer Hospital

Changling Li

National Cancer Center/National Clinical Research Center for Cancer/Cancer Hospital

\section{Research Article}

Keywords: tumor morphology, prognosis, ratio of maximum to minimum tumor diameter, metastatic renal cell carcinoma

Posted Date: January 11th, 2022

DOI: https://doi.org/10.21203/rs.3.rs-1183282/v1

License: (c) (i) This work is licensed under a Creative Commons Attribution 4.0 International License. Read Full License 


\section{Abstract}

Background: Several models and markers were developed and found to predict outcome of advanced renal cell carcinoma. This study aimed to evaluate the prognostic value of the ratio of maximum to minimum tumor diameter (ROD) in metastatic clear cell renal cell carcinoma (mccRCC).

Methods: Patients with mccRCC ( $n=213)$ treated with sunitinib from January 2008 to December 2018 were identified. Cut-off value for ROD was determined using receiver operating characteristic. Patients with different ROD scores were grouped and evaluated. Survival outcomes were estimated by KaplanMeier method.

Results: The optimal ROD cutoff value of 1.34 was determined for progression free survival (PFS) and overall survival (OS). Patients in ROD $\geq 1.34$ group had shorter PFS (9.6 versus 17.7 months, $p<0.001$ ) and OS (25.5 versus 32.6 months, $p<0.001)$ than patients in ROD<1.34 group. After adjustment for other factors, multivariate analysis showed ROD $\geq 1.34$ was an independent prognostic factor for PFS $(p<0.001)$ and $O S(p=0.006)$. Patients in $R^{2} D^{3} 1.34$ group presented higher proportions of $T 3 / 4$ stage (92.9\% versus $7.1 \%, p=0.012)$, WHO/ISUP grade III/IV (72.0\% versus $28.0 \%, p=0.010)$, tumor necrosis (71.0\% versus $29.0 \%, p=0.039)$, sarcomatoid differentiation $(79.1 \%$ versus $20.9 \%, p=0.007$ ), poor MSKCC risk score $(78.4 \%$ versus $21.6 \%, p<0.001)$ and poor IMDC risk score $(74.4 \%$ versus $25.6 \%, p<0.001)$ than $\mathrm{ROD}<1.34$ group.

Conclusion: Primary tumor with higher ROD was an independently prognostic factor for both PFS and OS in patients with mccRCC who received targeted therapy. Higher ROD was also associated with high T stage, high WHO/ISUP grade, sarcomatoid features, tumor necrosis, poor MSKCC and IMDC risk score.

\section{Background}

Renal cell carcinoma (RCC) accounts for approximately $3 \%$ of malignant tumors in adults and $20-30 \%$ of them are diagnosed as advanced diseases with poor prognosis $(1,2)$. Targeted therapy has been the standard metastatic RCC treatment since 2005(3,4). Several risk score models, such as the Memorial Sloan Kettering Cancer Center (MSKCC) system and the International Metastatic Renal Cell Carcinoma Database Consortium (IMDC) criteria, have been found and validated to predict the prognosis of different patients with metastatic RCC $(5,6)$. However, MSKCC and IMDC classification mostly focus on the state of the performance status and laboratory values while the primary tumor status has not been involved in.

Several studies have reported primary tumor size may be associated with prognosis of metastatic RCC(7, 8). It is still controversial and cannot completely reflect the role of primary tumor. The ratio of maximum to minimum tumor diameter (ROD), a specific primary tumor feature, has not been mentioned. Previously, we have investigated the utility of ROD in predicting pathologic subtypes of RCC before surgery and found its association with adverse pathological factors(9). We used ROD to quantify tumor irregularity. The more irregular the tumor, the higher the degree of malignancy was discovered. To further demonstrate the prognostic value of the ROD, in this study, we retrospectively analyzed the records of 
clear cell RCC (ccRCC) patients treated by surgery and followed sunitinib due to subsequent or simultaneous metastasis.

\section{Patients And Methods Patient selection}

This is a retrospective study focusing on patients with metastatic ccRCC (mccRCC), which was approved by the Domain-Specific Review Board Ethics Committee. Patient consent for treatment and follow-up was included in each medical record. Patients diagnosed as CCRCC after surgery and treated with sunitinib for metastasis between January 2008 and December 2018 were collected. Metastasis was confirmed by imaging examination. Sunitinib was initially administered $50 \mathrm{mg}$ once daily, on a $4 / 2$ schedule. Patients received other systematic therapies after sunitinib treatment failure, including pazopanib, everolimus, axitinib, immune checkpoint inhibitors, or other free second-line therapy trials. Clinicopathological features, such as age, gender, Karnofsky performance status, presenting symptom, tumor size, World Health Organization/International Society of Urologic Pathologists (WHO/ISUP) grade, tumor necrosis, sarcomatoid differentiation, MSKCC and IMDC criteria were used to evaluate.

\section{Radiological Assessment}

Patients had contrast-enhanced computed tomography (CT) or magnetic resonance imaging (MRI) examination within 2 weeks before surgery for primary tumor diagnosis and clinical staging. CT scans were undertaken every 4-8 week since taking sunitinib, and the Response Evaluation Criteria in Solid Tumors (RECIST) criteria version 1.1 were used to evaluate(10). The best response of treatment, including complete response (CR), partial response (PR), stable disease (SD) and progression disease (PD) was recorded.

The diameters of the tumor were measured including coronal, sagittal and axial view, including a maximum diameter, a sub maximum diameter and a minimum diameter in clinical staging before surgery (Figure 1). Tumor's three diameters were recorded separately by 2 independent radiologists. The ratio of the maximum diameter to the minimum diameter (ROD) was calculated to quantify tumor irregularity.

\section{Statistical analysis}

Chi-square test, Fisher's exact test or Student's t-test were used to analyze the relationship of different groups. The optimal cutoff value of ROD in prediction of survival outcomes was determined by Receiver Operating Characteristic (ROC) curve analysis. To investigate the survival outcome of patients with mccRCC, progression-free survival (PFS) and overall survival (OS) from the initiation of sunitinib were determined using the Kaplan-Meier method and were analyzed using the log-rank test. Cox proportional hazards regression models were used to assess the significant factors unadjusted and adjusted for 
covariates. Statistical analysis was performed using SPSS 23.0 software, and differences were considered statistically significant if $p$ values were $<0.05$.

\section{Results}

\section{Patients' characteristics}

A total of 213 patients with a median age of 55.0 years (range, 17-76 years) were identified. Patients included $139(65.3 \%)$ males and 74 (34.7\%) females. Median primary tumor size measured in CT or MRI was $6.1 \mathrm{~cm}$ (range, 1.1-15.6 cm). The number of patients in T1a, T1b, T2a, T2b, T3 and T4 stage was 23 (10.8\%), 117 (54.9\%), 45 (21.1\%), 14 (6.6\%), 8 (3.8\%), and 6 (2.8\%) respectively. All patients were received nephrectomy before systemic therapy. Patients consisted of 96 (45.1\%) cases of synchronous RCC and 117 (54.9\%) cases of metachronous RCC. The most common site of metastasis was pulmonary in 164 cases $(77.0 \%)$, followed by lymph node metastasis in 86 cases $(40.4 \%)$. Other metastases included bone, adrenal, liver, brain, spleen, and pancreas. There were 152 patients $(71.4 \%)$ harboring more than 2 metastatic organs. Twenty-two patients (10.3\%) had responders including CR $(n=5,2.3 \%)$ and PR $(n=17$, 8.0\%) during the treatment of sunitinib. Patients' characteristics were summarized in Table 1. 
Table 1

Correlation between ROD and the clinicopathological features of patients with metastatic renal cell carcinoma.

\begin{tabular}{|c|c|c|c|c|}
\hline Characteristics & Total & $\begin{array}{l}\text { ROD }<1.34(n= \\
83)\end{array}$ & $\begin{array}{l}R O D \\
130)\end{array}$ & $p$ value \\
\hline Age at sunitinib (mean \pm SD) & $\begin{array}{l}53.3 \pm \\
9.8\end{array}$ & $52.1 \pm 10.7$ & $54.1 \pm 9.2$ & 0.139 \\
\hline Gender, n (\%) & & & & 0.961 \\
\hline Man & $\begin{array}{l}139 \\
(65.3)\end{array}$ & $54(38.8)$ & $85(61.2)$ & \\
\hline Woman & $74(34.7)$ & $29(39.2)$ & $45(60.8)$ & \\
\hline KPS score < 80, n (\%) & $15(7.0)$ & $5(33.3)$ & $10(66.7)$ & 0.643 \\
\hline Presenting symptom, n (\%) & $19(8.9)$ & $7(36.8)$ & $12(63.2)$ & 0.842 \\
\hline Tumor size (mean \pm SD) & $6.3 \pm 2.2$ & $6.7 \pm 2.1$ & $6.1 \pm 2.2$ & 0.089 \\
\hline Tumor location, n (\%) & & & & 0.182 \\
\hline Left & $\begin{array}{l}102 \\
(47.9)\end{array}$ & $35(34.3)$ & $67(65.7)$ & \\
\hline Right & $\begin{array}{l}111 \\
(52.1)\end{array}$ & $48(43.2)$ & $63(56.8)$ & \\
\hline Type of metastasis & & & & 0.908 \\
\hline Synchronous & $96(45.1)$ & $37(24.0)$ & $59(76.0)$ & \\
\hline Metachronous & $\begin{array}{l}117 \\
(54.9)\end{array}$ & $46(51.3)$ & $71(48.7)$ & \\
\hline T stage, n (\%) & & & & 0.012 \\
\hline $\mathrm{T} 1 / 2$ & $\begin{array}{l}199 \\
(93.4)\end{array}$ & $82(41.2)$ & $117(58.8)$ & \\
\hline $\mathrm{T} 3 / 4$ & $14(6.6 \%)$ & $1(7.1)$ & $13(92.9)$ & \\
\hline WHO/ISUP grade, n (\%) & & & & 0.010 \\
\hline I/II & $\begin{array}{l}131 \\
(61.5)\end{array}$ & $60(45.8)$ & $71(54.2)$ & \\
\hline III/IV & $82(38.5)$ & $23(28.0)$ & $59(72.0)$ & \\
\hline Tumor necrosis, n (\%) & $69(32.4)$ & $20(29.0)$ & 49 (71.0) & 0.039 \\
\hline
\end{tabular}

Abbreviations: ROD, Ratio of maximum to minimum tumor diameter; KPS, Karnofsky performance status; WHO/ISUP, World Health Organization/International Society of Urologic Pathologists; MSKCC, Memorial Sloan Kettering Cancer Center; IMDC, International Metastatic Renal Cell Carcinoma Database Consortium. 


\begin{tabular}{|c|c|c|c|c|}
\hline Characteristics & Total & $\begin{array}{l}\text { ROD }<1.34(n= \\
83)\end{array}$ & $\begin{array}{l}\mathrm{ROD} \geq 1.34(n= \\
130)\end{array}$ & $\mathrm{p}$ value \\
\hline $\begin{array}{l}\text { Sarcomatoid differentiation, } \mathrm{n} \\
(\%)\end{array}$ & $43(20.2)$ & 9 (20.9) & $34(79.1)$ & 0.007 \\
\hline \multicolumn{2}{|l|}{ MSKCC risk classification } & & & $<.001$ \\
\hline Good & $\begin{array}{l}102 \\
(47.9)\end{array}$ & $59(57.8)$ & $43(42.2)$ & \\
\hline Intermediate and poor & $\begin{array}{l}111 \\
(52.1)\end{array}$ & $24(21.6)$ & $87(78.4)$ & \\
\hline \multicolumn{2}{|l|}{ IMDC risk classification } & & & $\begin{array}{l}<.001 \\
0.001\end{array}$ \\
\hline Good & $92(43.2)$ & $52(56.5)$ & $40(43.5)$ & \\
\hline Intermediate and poor & $\begin{array}{l}121 \\
(56.8)\end{array}$ & $31(25.6)$ & $90(74.4)$ & \\
\hline \multicolumn{2}{|l|}{ Number of metastatic organs } & & & 0.943 \\
\hline$<2$ & $61(28.6)$ & $24(39.3)$ & $37(60.7)$ & \\
\hline$\geq 2$ & $\begin{array}{l}152 \\
(71.4)\end{array}$ & $59(38.8)$ & $93(61.2)$ & \\
\hline \multicolumn{2}{|l|}{ Response to sunitinib, $\mathrm{n}(\%)$} & & & 0.844 \\
\hline Responder & $22(10.3)$ & $9(40.9)$ & $13(59.1)$ & \\
\hline Non-responder & $\begin{array}{l}191 \\
(89.7)\end{array}$ & $74(38.7)$ & $117(61.3)$ & \\
\hline \multicolumn{5}{|c|}{$\begin{array}{l}\text { Abbreviations: ROD, Ratio of maximum to minimum tumor diameter; KPS, Karnofsky performance } \\
\text { status; WHO/ISUP, World Health Organization/International Society of Urologic Pathologists; MSKCC, } \\
\text { Memorial Sloan Kettering Cancer Center; IMDC, International Metastatic Renal Cell Carcinoma } \\
\text { Database Consortium. }\end{array}$} \\
\hline
\end{tabular}

\section{The Association Between Rod And Clinicopathological Features}

ROC curves were constructed to determine the appropriate cut-off point of ROD (Supplementary figure 1). The most discriminative ROD cutoff value of 1.34 was selected for both PFS (sensitivity $=79.3 \%$, specificity $=74.0 \%$; Area Under Curve, AUC $=0.810,95 \%$ confidence interval, $\mathrm{Cl}: 0.752-0.869, \mathrm{p}<0.001$ ) and OS (sensitivity $=84.9 \%$, specificity $=83.8 \%$; AUC $=0.932,95 \% \mathrm{Cl}: 0.899-0.966, \mathrm{p}<0.001$ ). The patients were divided into two groups including $R O D<1.34$ group $(n=83)$ and $R O D \geq 1.34$ group $(n=130)$. Comparison between ROD and the Clinicopathological features were showed in Table 1. Patients in ROD $\geq 1.34$ group presented higher proportions of T3/4 stage $(92.9 \%$ versus $7.1 \%, \mathrm{p}=0.012)$, WHO/ISUP grade III/IV $(72.0 \%$ 
versus $28.0 \%, p=0.010)$, tumor necrosis $(71.0 \%$ versus $29.0 \%, p=0.039)$, sarcomatoid differentiation (79.1\% versus $20.9 \%, p=0.007)$, poor MSKCC risk score $(78.4 \%$ versus $21.6 \%, p<0.001)$ and poor IMDC risk score $(74.4 \%$ versus $25.6 \%, p<0.001)$ than $R O D<1.34$ group.

\section{The Evaluation Of Rod In Clinical Outcomes}

After 32.0 months (range, 2.6-125.8 months) median follow-up, patients in ROD $\geq 1.34$ group experienced significantly shorter PFS (median, 9.6 versus 17.7 months, $p<0.001$ ) and OS (median, 25.5 versus 32.6 months, $p<0.001$ ) than patients in ROD $<1.34$ group (Figure 2 ).

The univariate survival analysis revealed that ROD $\geq 1.34$ ( $p<0.001)$, WHO/ISUP grade $(p<0.001)$, tumor necrosis $(p=0.032)$, sarcomatoid differentiation $(p<0.001)$, MSKCC score $(p<0.001)$ and IMDC score $(p<0.001)$ appeared as significant prognostic factors for PFS (Table 2$)$. After adjustment for WHO/ISUP grade $(p<0.001)$, tumor necrosis $(p=0.118)$, sarcomatoid differentiation $(p=0.035)$, MSKCC score $(p=0.008)$ and IMDC score $(p<0.001)$, the multivariate Cox regression analysis revealed that $R O D \geq 1.34$ (adjusted hazard ratio, HR=3.068, 95\% Cl:2.102-4.478, $p<0.001$ ) was an independent prognostic factor for poor PFS (Table 3$)$. In addition, presenting symptom ( $p=0.007), R O D \geq 1.34(p<0.001)$, WHO/ISUP grade $(p<0.001)$, tumor necrosis $(p=0.007)$, sarcomatoid differentiation $(p=0.016)$, MSKCC score $(p<0.001)$ and IMDC score $(p<0.001)$ were prognostic factors for OS (Table 2$)$. After adjustment for presenting symptom $(p=0.009)$, WHO/ISUP grade $(p<0.001)$, tumor necrosis $(p<0.001)$, sarcomatoid differentiation $(p=0.621)$, MSKCC score $(p=0.002)$ and IMDC score $(p<0.001), R O D \geq 1.34$ (adjusted HR=1.774, 95\% Cl:1.175-2.676, $p=0.006$ ) was still an independent prognostic factors for OS (Table 3 ). 
Table 2

Univariate Cox regression analysis of clinical factors in patients with metastatic renal cell carcinoma

Progression free survival

\begin{tabular}{|c|c|c|c|c|c|c|}
\hline Variable & $\mathrm{HR}$ & $95 \% \mathrm{Cl}$ & $\begin{array}{l}\mathrm{p} \\
\text { value }\end{array}$ & $\mathrm{HR}$ & $95 \% \mathrm{Cl}$ & $\begin{array}{l}\mathrm{p} \\
\text { value }\end{array}$ \\
\hline Age & 1.003 & $\begin{array}{l}0.988- \\
1.019\end{array}$ & 0.653 & 1.001 & $\begin{array}{l}0.985- \\
1.018\end{array}$ & 0.871 \\
\hline Gender, male & 0.936 & $\begin{array}{l}0.677- \\
1.293\end{array}$ & 0.688 & 0.829 & $\begin{array}{l}0.586- \\
1.173\end{array}$ & 0.290 \\
\hline $\mathrm{KPS},<80$ & 1.064 & $\begin{array}{l}0.520- \\
2.177\end{array}$ & 0.864 & 0.577 & $\begin{array}{l}0.212- \\
1.569\end{array}$ & 0.281 \\
\hline Presenting symptom & 1.292 & $\begin{array}{l}0.770- \\
2.168\end{array}$ & 0.332 & 2.256 & $\begin{array}{l}1.247- \\
4.082\end{array}$ & 0.007 \\
\hline Tumor location, left & 1.027 & $\begin{array}{l}0.753- \\
1.400\end{array}$ & 0.867 & 1.073 & $\begin{array}{l}0.769- \\
1.497\end{array}$ & 0.678 \\
\hline $\mathrm{ROD}, \geq 1.34$ & 3.974 & $\begin{array}{l}2.784- \\
5.673\end{array}$ & $<.001$ & 2.783 & $\begin{array}{l}1.927- \\
4.018\end{array}$ & $\begin{array}{l}< \\
0.001\end{array}$ \\
\hline T stage, $3 / 4$ & 1.116 & $\begin{array}{l}0.774- \\
1.628\end{array}$ & 0.052 & 1.059 & $\begin{array}{l}0.927- \\
1.253\end{array}$ & \\
\hline WHO/ISUP grade, III/IV & 2.308 & $\begin{array}{l}1.684- \\
3.165\end{array}$ & $<.001$ & 3.164 & $\begin{array}{l}2.249- \\
4.415\end{array}$ & $\begin{array}{l}<.001 \\
0.001\end{array}$ \\
\hline Tumor necrosis & 1.438 & $\begin{array}{l}1.031- \\
2.007\end{array}$ & 0.032 & 1.677 & $\begin{array}{l}1.167- \\
2.410\end{array}$ & 0.007 \\
\hline $\begin{array}{l}\text { Number of metastatic organs, } \geq \\
2\end{array}$ & 1.053 & $\begin{array}{l}0.728- \\
1.547\end{array}$ & 0.468 & 0.459 & $\begin{array}{l}0.592- \\
1.426\end{array}$ & 0.584 \\
\hline Sarcomatoid differentiation & 2.131 & $\begin{array}{l}1.455- \\
3.120\end{array}$ & $<.001$ & 1.722 & $\begin{array}{l}1.107- \\
2.680\end{array}$ & 0.016 \\
\hline $\begin{array}{l}\text { MSKCC score, intermediate and } \\
\text { poor }\end{array}$ & 2.624 & $\begin{array}{l}1.895- \\
3.634\end{array}$ & $<.001$ & 3.125 & $\begin{array}{l}2.174- \\
4.493\end{array}$ & $\begin{array}{l}< \\
0.001\end{array}$ \\
\hline $\begin{array}{l}\text { IMDC score, intermediate and } \\
\text { poor }\end{array}$ & 3.342 & $\begin{array}{l}2.116- \\
6.528\end{array}$ & $<.001$ & 4.317 & $\begin{array}{l}2.383- \\
6.657\end{array}$ & $<.001$ \\
\hline
\end{tabular}

Abbreviations: KPS, Karnofsky performance status; ROD, Ratio of maximum to minimum tumor diameter; WHO/ISUP, World Health Organization/International Society of Urologic Pathologists; MSKCC, Memorial Sloan Kettering Cancer Center; IMDC, International Metastatic Renal Cell Carcinoma Database Consortium. 
Table 3

Independent prognostic factors analyzed using a multivariable Cox model in patients with metastatic renal cell carcinoma

\begin{tabular}{|c|c|c|c|c|c|c|}
\hline \multirow[b]{2}{*}{ Variable } & \multicolumn{3}{|c|}{ Progression free survival } & \multicolumn{3}{|c|}{ Overall survival } \\
\hline & $\mathrm{HR}$ & $95 \% \mathrm{Cl}$ & $\begin{array}{l}\mathrm{p} \\
\text { value }\end{array}$ & $H R$ & $95 \% \mathrm{Cl}$ & $\begin{array}{l}\mathrm{p} \\
\text { value }\end{array}$ \\
\hline Presenting symptom & & & & 2.219 & $\begin{array}{l}1.220- \\
4.037\end{array}$ & 0.009 \\
\hline $\mathrm{ROD}, \geq 1.34$ & 3.068 & $\begin{array}{l}2.102- \\
4.478\end{array}$ & $<001$ & 1.774 & $\begin{array}{l}1.175- \\
2.676\end{array}$ & 0.006 \\
\hline WHO/ISUP grade, III/IV & 2.102 & $\begin{array}{l}1.512- \\
2.922\end{array}$ & $<.001$ & 2.699 & $\begin{array}{l}1.880- \\
3.874\end{array}$ & $\dot{0.001}$ \\
\hline Tumor necrosis & 1.315 & $\begin{array}{l}0.933- \\
1.854\end{array}$ & 0.118 & 2.046 & $\begin{array}{l}1.395- \\
3.002\end{array}$ & $<.001$ \\
\hline Sarcomatoid differentiation & 1.529 & $\begin{array}{l}1.031- \\
2.268\end{array}$ & 0.035 & 1.123 & $\begin{array}{l}0.710- \\
1.776\end{array}$ & 0.621 \\
\hline $\begin{array}{l}\text { MSKCC score, intermediate and } \\
\text { poor }\end{array}$ & 1.619 & $\begin{array}{l}1.137- \\
2.305\end{array}$ & 0.008 & 1.901 & $\begin{array}{l}1.261- \\
2.864\end{array}$ & 0.002 \\
\hline $\begin{array}{l}\text { IMDC score, intermediate and } \\
\text { poor }\end{array}$ & 2.315 & $\begin{array}{l}1.427- \\
4.438\end{array}$ & $<.001$ & 2.004 & $\begin{array}{l}1.258- \\
4.062\end{array}$ & $\dot{0.001}$ \\
\hline $\begin{array}{l}\text { Abbreviations: ROD, Ratio of mar } \\
\text { Organization/International Socie } \\
\text { Cancer Center; IMDC, Internation }\end{array}$ & $\begin{array}{l}n \text { to } n \\
\text { Urolo }\end{array}$ & imum & $\begin{array}{l}\text { liame } \\
\text { MSK }\end{array}$ & ISUP, & $\begin{array}{l}\text { Vorld H } \\
\text { pan Ket } \\
\text { hsortiur }\end{array}$ & \\
\hline
\end{tabular}

\section{Discussion}

From published papers, intratumor heterogeneity is a key factor contributing to the survival of cancer, therapeutic failure, and drug resistance $(11,12)$. The scale of heterogeneity within a tumor has also been found and proved in $\operatorname{RCC}(13,14)$. Studies have showed that intratumor heterogeneity may contribute to the polyclonal growth pattern of tumors(15). In addition, polyclonal growth commonly accompanies with corresponding change of tumor microenvironment, which is also thought to play an important role for tumor growth and progression and to be involved in the treatment outcome of targeted therapy(16). We considered that the intratumor heterogeneity evolved to the asymmetric tumor morphology. From the clinical practice, we observed that the ROD could be used to quantify the tumor irregularity. The higher the intratumor heterogeneity, the more irregular tumor and the higher ROD would achieve, which was likely to reveal the efficacy of later treatment.

The ROD, a specific feature of primary tumor, has not been investigated before. In this study, the most optimal ROD cutoff value of 1.34 was determined. Patients in ROD $\geq 1.34$ group accounted for $61.0 \%$ $(130 / 213)$. In this study, we were not surprised to find that more cases of metastatic renal cell carcinoma 
were in the group with larger ROD. This finding suggested a new hypothesis that the stronger tumor heterogeneity have more chances of metastasis.

We found that the ROD $\geq 1.34$ was also significantly associated with prognosis. Compared with patients in $R O D \geq 1.34$ group, patients in ROD $<1.34$ group achieved longer PFS ( 17.7 versus 9.6 months, $p<0.001)$ and OS (32.6 versus 25.5 months, $p<0.001$ ). Variable pathology factors including WHO/ISUP grade, tumor necrosis, and sarcomatoid differentiation were also associated with outcome of RCC, which were confirmed in previous studies(17-19). In this study, these features were also investigated. WHO/ISUP grade, sarcomatoid differentiation, MSKCC score and IMDC score were independent prognostic factors for PFS, and presenting symptom, WHO/ISUP grade, tumor necrosis, MSKCC score and IMDC score were independent prognostic factors for OS. Interestingly, we found that patients in ROD $\geq 1.34$ group were more likely to present high WHO/ISUP grade, high T stage, tumor necrosis, sarcomatoid differentiation, poor MSKCC risk score, and poor IMDC score. Besides above findings, after adjustment for significant variables, we also found that $R O D \geq 1.34$ was an independent prognostic factor for both poor PFS and OS.

In addition, ROD $\geq 1.34$ was associated with high T stage (3/4), high WHO/ISUP grade, sarcomatoid features, tumor necrosis, poor MSKCC risk score and poor IMDC score. This showed that as an index to quantify tumor irregularity, ROD had a strong relationship with tumor malignancy.

Our study includes several limitations that need to be acknowledged. It was a retrospective study including limited cases, which still needed to accumulate data, and we will carry out prospective studies to confirm. In addition, we will further explore the possible molecular mechanism of poor outcome associated with irregularity of primary tumor.

\section{Conclusions}

Primary tumor with ROD $\geq 1.34$ was an independently prognostic factor for both PFS and OS in patients with mccRCC who received targeted therapy and also associated with high T stage, high WHO/ISUP grade, sarcomatoid features, tumor necrosis, poor MSKCC and IMDC risk score. Further prospective validation is required to confirm these findings.

\section{Abbreviations}

AUC: Area Under Curve

Cl: confidence interval

CR: complete response

CT: computed tomography

HR: hazard ratio 
IMDC: International Metastatic Renal Cell Carcinoma Database Consortium

mccRCC: metastatic clear cell renal cell carcinoma

mRCC: metastatic RCC

MRI: magnetic resonance imaging

MSKCC: Memorial Sloan Kettering Cancer Center

NCC/CHCAMS: National Cancer Center/Cancer Hospital, Chinese Academy of Medical Sciences

OS: overall survival

PD: progression disease

PFS: progression-free survival

PR: partial response

RCC: Renal cell carcinoma

RECIST: Response Evaluation Criteria in Solid Tumors

ROC: Receiver Operating Characteristic

ROD: ratio of maximum to minimum tumor diameter

SD: stable disease

WHO/ISUP: World Health Organization/International Society of Urologic Pathologists

\section{Declarations}

\section{Ethics approval and consent to participate}

The research study was reviewed and approved by the Domain-Specific Review Board, Cancer Hospital Chinese Academy of Medical Sciences (ID: NCC2016YJC-08). Patient details were anonymized before analysis. Patient written informed consent for treatment and follow-up was included in each medical record. All methods were carried out in accordance with relevant guidelines and regulations.

\section{Consent for publication}

Not applicable.

\section{Availability of data and materials}


The datasets generated and/or analysed during the current study are not publicly available due to individual privacy could be compromised but are available from the corresponding author on reasonable request.

\section{Competing interests}

The authors declare no conflicts of interests.

\section{Funding}

This work was supported by Beijing hope run special fund of cancer foundation of China (LC2018L02).

\section{Authors' contributions}

All authors listed in this manuscript contributed significantly to the study. Shi HZ and Cao CZ contributed to writing the manuscript. Wen L contributed to clinical data collection and analysis. Zhang LY and Zhang $\mathrm{J}$ contributed to reviewing CT or MRI data. Ma JH contributed to conception of the study. Li CL and Shou $\mathrm{JZ}$ contributed to the study design and reviewed the manuscript for critical revisions. All authors read and approved the final manuscript.

\section{Acknowledgements}

Not applicable.

\section{References}

1. Siegel RL, Miller KD, Jemal A. Cancer statistics, 2019. CA: a cancer journal for clinicians. 2019;69(1):7-34.

2. Capitanio U, Bensalah K, Bex A, Boorjian SA, Bray F, Coleman J, et al. Epidemiology of Renal Cell Carcinoma. European urology. 2019;75(1):74-84.

3. Moran M, Nickens D, Adcock K, Bennetts M, Desscan A, Charnley N, et al. Sunitinib for Metastatic Renal Cell Carcinoma: A Systematic Review and Meta-Analysis of Real-World and Clinical Trials Data. Targeted oncology. 2019;14(4):405-16.

4. Motzer RJ, Hutson TE, Tomczak P, Michaelson MD, Bukowski RM, Oudard S, et al. Overall survival and updated results for sunitinib compared with interferon alfa in patients with metastatic renal cell carcinoma. Journal of clinical oncology: official journal of the American Society of Clinical Oncology. 2009;27(22):3584-90.

5. Escudier B, Porta C, Schmidinger M, Rioux-Leclercq N, Bex A, Khoo V, et al. Renal cell carcinoma: ESMO Clinical Practice Guidelines for diagnosis, treatment and follow-up. Annals of oncology: official journal of the European Society for Medical Oncology. 2016;27(suppl 5):v58-v68.

6. Heng DY, Xie W, Regan MM, Warren MA, Golshayan AR, Sahi C, et al. Prognostic factors for overall survival in patients with metastatic renal cell carcinoma treated with vascular endothelial growth 
factor-targeted agents: results from a large, multicenter study. Journal of clinical oncology: official journal of the American Society of Clinical Oncology. 2009;27(34):5794-9.

7. DiNatale RG, Xie W, Becerra MF, Silagy AW, Attalla K, Sanchez A, et al. The Association Between Small Primary Tumor Size and Prognosis in Metastatic Renal Cell Carcinoma: Insights from Two Independent Cohorts of Patients Who Underwent Cytoreductive Nephrectomy. European urology oncology. 2020;3(1):47-56.

8. Thompson RH, Hill JR, Babayev Y, Cronin A, Kaag M, Kundu S, et al. Metastatic renal cell carcinoma risk according to tumor size. The Journal of urology. 2009;182(1):41-5.

9. Jiang W, Wang D, Shi H, Shang B, Wen L, Zhang L, et al. Ratio of maximum to minimum tumor diameter can predict the pathology type of renal cell carcinoma before surgery. Tumori. 2021;107(1):64-70.

10. Eisenhauer EA, Therasse P, Bogaerts J, Schwartz LH, Sargent D, Ford R, et al. New response evaluation criteria in solid tumours: revised RECIST guideline (version 1.1). European journal of cancer (Oxford, England: 1990). 2009;45(2):228-47.

11. McGranahan N, Swanton C. Biological and therapeutic impact of intratumor heterogeneity in cancer evolution. Cancer cell. 2015;27(1):15-26.

12. Greaves M. Evolutionary determinants of cancer. Cancer discovery. 2015;5(8):806-20.

13. Martinez P, Birkbak NJ, Gerlinger M, McGranahan N, Burrell RA, Rowan AJ, et al. Parallel evolution of tumour subclones mimics diversity between tumours. The Journal of pathology. 2013;230(4):35664.

14. Gerlinger M, Horswell S, Larkin J, Rowan AJ, Salm MP, Varela I, et al. Genomic architecture and evolution of clear cell renal cell carcinomas defined by multiregion sequencing. Nature genetics. 2014;46(3):225-33.

15. McGranahan N, Swanton C. Clonal Heterogeneity and Tumor Evolution: Past, Present, and the Future. Cell. 2017;168(4):613-28.

16. Olson OC, Joyce JA. Microenvironment-mediated resistance to anticancer therapies. Cell research. 2013;23(2):179-81.

17. Zhang L, Zha Z, Qu W, Zhao H, Yuan J, Feng Y, et al. Tumor necrosis as a prognostic variable for the clinical outcome in patients with renal cell carcinoma: a systematic review and meta-analysis. BMC cancer. 2018;18(1):870.

18. Chrom P, Stec R, Semeniuk-Wojtas A, Bodnar L, Spencer NJ, Szczylik C. Fuhrman Grade and Neutrophil-To-Lymphocyte Ratio Influence on Survival in Patients With Metastatic Renal Cell Carcinoma Treated With First-Line Tyrosine Kinase Inhibitors. Clinical genitourinary cancer. 2016;14(5):457-64.

19. Kim T, Zargar-Shoshtari K, Dhillon J, Lin HY, Yue B, Fishman M, et al. Using percentage of sarcomatoid differentiation as a prognostic factor in renal cell carcinoma. Clinical genitourinary cancer. 2015;13(3):225-30. 


\section{Figures}

\section{Figure 1}

Example of measuring the three diameters: one maximum, one sub maximum, and one minimum.

\section{Figure 2}

Patients with $\operatorname{ROD}^{3} 1.34$ had shorter progression free survival $(A)$ and overall survival $(B)$ than patients with $\mathrm{ROD}<1.34$.

\section{Supplementary Files}

This is a list of supplementary files associated with this preprint. Click to download.

- Supplementaryfigure1.tif 